\title{
Peer Instruction versus Class-wide Discussion in Large Classes: a comparison of two interaction methods in the wired classroom
}

\author{
DAVID J. NICOL
}

Centre for Academic Practice, University of Strathclyde, UK

\section{JAMES T. BOYLE}

Department of Mechanical Engineering, University of Strathclyde, UK

\begin{abstract}
Following concerns about the poor conceptual understanding shown by science students, two US research groups have been experimenting with the use of 'classroom communication systems' (CCSs) to promote dialogue in large classes. CCS technology makes it easier to give students immediate feedback on concept tests and to manage peer and class discussions. Improvements in conceptual reasoning have been shown using these methods. However, these research groups have each piloted different discussion sequences. Hence, little is known about which sequence is best and under what circumstances. This study compares the effects of each sequence on students' experiences of learning engineering in a UK university. The research methods included interviezws, a survey and a critical incident questionnaire. The results demonstrated that the type of dialogue and the discussion sequence have important effects on learning. The findings are discussed in relation to social constructivist theories of learning and in relation to the implications for teaching in wired classrooms.
\end{abstract}

\section{Introduction}

Many of the core concepts in science and engineering are complex and counter-intuitive. Hence, university students taking introductory classes in these disciplines, even those with high entry qualifications, often have difficulty learning these concepts and applying them to problem-solving tasks (e.g. McDermott, 1984; Brumby, 1984; Halloun \& Hestenes, 1985; West \& Pines, 1985; Mazur, 1997). One way to tackle this difficulty is to engage students in active discussion in situations where their current understandings will be challenged and they can experiment with alternative conceptualisations (McDermott, 1984; Halloun \& Hestenes, 1985; Hake, 1998). Learning environments that are dialogically rich-embodying teacherstudent and/or student-student dialogue-are known to develop critical thinking and deep conceptual understanding in students (e.g. Reiter, 1994; Anderson et al., 1996, 2001; deCorte, 1996; Matthews, 1996). However, the growth of mass higher education, with increased numbers of students per class, makes it difficult for the teacher to implement methods centred on dialogue and discussion.

Over the past decade, many higher education teachers have been experimenting with ways of making large lecture classes more interactive (Bligh, 2000; MacGregor et al., 2000; 
Edwards et al., 2001). Typical techniques involve stopping lectures at intervals to engage students in question-answer sessions or in pair or small group discussions. Yet, there are limitations with these methods and especially when class sizes are very large (e.g. over 100); for example, it can be difficult and time-consuming to manage alternations of lecturer input and discussion, to elicit systematic feedback on learning or to ensure that all students are actively involved.

In an attempt to improve concept learning in the sciences, some higher education researchers in the USA have harnessed developments in information and communications technology to help support the management of interaction and discussion in large classes. Using 'Classroom Communication Systems' (or classroom feedback systems) the Physics Education Research Group (PERG) at the University of Massachusetts (Dufresne et al., 1996) and researchers within the Galileo Project at Harvard (Mazur, 1997; Crouch \& Mazur, 2001) have modified the traditional lecture format in science education. They have refocused teaching on core concepts in the discipline using a sequence that involves cycles of short presentations followed by concept questions (tests), immediate feedback and peer group and/or class-wide discussion.

The main components of a Classroom Communication System (CCS) are a computer, a data projector to present the concept tests (normally a multiple-choice question aimed at testing students' understanding of a concept), a set of handsets (transmitters similar to television \& video remote controls), sensors (receivers) that allow students to signal their responses to the concept test, and software that allows class responses to be collated and immediately displayed as a histogram for students to see (i.e. fed back to students). This feedback is normally used as the trigger to initiate small group or class-wide discussion.

While the intention of both the Harvard and Massachusetts researchers has been to enhance the dialogue associated with learning, each research group has pioneered a somewhat different discussion sequence. In 'peer instruction' (Mazur, 1997) the students usually respond to the concept test individually, then they discuss their responses, and the underlying reasoning, in small groups before being retested (on the same concept question). In contrast, the PERG approach (Dufresne et al., 1996), called 'class-wide discussion', begins with small group discussion of the concept question, followed by an individual or group response. The students then engage in class-wide discussion facilitated by the teacher: for example, the teacher might encourage discussion across peer groups by asking different students to explain to the class their reasoning for an answer.

There is a great deal of research indicating that peer instruction and class-wide discussion, as implemented at Harvard and Massachusetts, lead to improvements in students' conceptual understanding (Mazur, 1997; Crouch \& Mazur, 2001), in student motivation, and in the quality of classroom discussion (Dufresne et al., 1996). Mazur (1997) has shown that students who normally struggle below the $50 \%$ mark in traditional examinations are lifted into a higher band with peer instruction: the grade distribution shows a positive change. Mazur's research indicates that a student who does not yet understand a concept is helped by talking the concept question through with a student who is in the early stages of his or her own comprehension.

Crouch and Mazur (2001) analysed 10 years of teaching a single, calculus-based physics course at Harvard using peer instruction. This longitudinal research demonstrated improved student mastery of conceptual reasoning and quantitative problem-solving over time and in a variety of contexts. It also showed that, after peer discussion, the number of students giving correct answers to a concept re-test substantially increased. According to Crouch and Mazur (2001), peer discussion is critical to the success of peer instruction: it encourages active engagement by students with the subject matter, a condition they feel is necessary for the development of complex reasoning skills. 
Dufresne et al. (1996) held interviews with mathematics and science teachers who were using CCSs to enable class-wide discussion in these subjects. They also interviewed students. The teachers reported that the CCS was a useful tool not only for engaging students in active learning but also for enhancing overall communication within the classroom. The students were also positive about CCS-facilitated learning, reporting that they learned more during a CCS class than during a traditional lecture class.

Dufresne et al.'s (1996) interpretation of the benefits of class-wide discussion is consistent with, but more developed than, that of Crouch and Mazur. They draw on the theoretical assumptions underlying 'constructivism' and 'social constructivism'. From constructivism comes the idea that conceptual understanding is primarily developed through activity: the learner actively constructs their own understanding of concepts and their interrelationships (see chapter 1 in Resnick, 1989; Glaser, 1990). Social constructivism emphasises the underlying social basis of knowledge construction: most learning is socially mediated, with individuals actively constructing their knowledge through dialogue with others (e.g. Doise \& Mugny, 1984; Brown et al., 1989; Lave \& Wenger, 1991). In effect, the PERG group believes that class-wide discussion is effective because the sequence of activities it entails 'challenges students to select, identify, and defend their choices of concepts and principles' in dialogue with other students and the teacher (Dufresne et al., 1996). The PERG group also argues that class-wide discussion improves the attitudes of students in class and their motivation to learn.

Despite the research showing that peer instruction and class-wide discussion lead to learning benefits, there are still some gaps in our understanding of the underlying processes. First, little is known about how students themselves experience these methods of learning or about which aspects of the learning environment contribute to their enhanced understanding. Secondly, although both Mazur (1997) and Dufresne et al. (1996) have demonstrated improvements in learning through dialogue, it is unclear from the literature which of the two discussion sequences-peer instruction or class-wide discussion-might be best and under what circumstances. A research programme was initiated to investigate both these concerns. In this article we report on the second issue-the comparison of students' perceptions of the effects of the different discussion sequences on their understanding and motivation. The students who took part in the investigation were studying engineering mechanics in a UK university. Given that all previous research in this area has been conducted in the USA, this research also allowed us to test the robustness of these discussion methods in a different cultural context. Elsewhere we report on other aspects of students' and teachers' experiences with these interactive methods (Boyle \& Nicol, 2003).

The article begins with some background context and an explanation of the design of the study and its methods of investigation. This is followed by the results of the comparison of the different discussion sequences. This section includes actual comments from students describing their experiences of, and attitudes to, these sequences as well as quantitative survey data. Finally, the findings are discussed in relation to social constructivist theories and in terms of the implications for teaching and learning in wired classrooms. The issues raised in this article, while discussed in terms of an engineering discipline, are relevant to teaching and learning in all disciplines.

\section{The NATALIE Project}

\section{Background Context}

In 1998 an initiative entitled 'New Approaches to Teaching and Learning in Engineering' (NATALIE) was launched at the University of Strathclyde. The intention was to develop a 
new model for first year Mechanical Engineering that would, over time, be rolled out across the undergraduate degree programme. NATALIE was driven by a concern that the teaching of the core engineering subjects, in particular Mechanics and Thermo-Fluids had not been achieving their aims. After a year of study, students seemed to have acquired a poor understanding of basic concepts. This was despite the fact that these students are amongst the highest qualified (at entry) in the University of Strathclyde and in engineering in the UK in general. Furthermore, these conceptual difficulties appeared to become amplified in later years of study.

Two years of preparation preceded the implementation of NATALIE. During that time staff from the Department of Mechanical Engineering visited and observed how engineering was taught in a range of US institutions and they became familiar with recent research on teaching and learning in higher education. The basic model developed through NATALIE draws on a decade of research in the USA in the sciences. The pedagogical framework centres on the idea of 'interactive engagement' (Hake, 1998), with the emphasis being on putting dialogue and active learning back into engineering education. This ranges from the use of 'problem-based learning' in design, to workshop/studio teaching in custom-built classrooms, to the reintroduction of more laboratory-intensive work. This article examines one aspect of the NATALIE initiative- the use of Classroom Communication Systems to support interaction and dialogue in large classes. The specific focus was an engineering mechanics class (a first year class) during the third year of the implementation of NATALIE.

\section{Technical Description of the Classroom Communication System}

In 1998 the Department of Mechanical Engineering modified a traditional lecture theatre so that it could accommodate up to 118 students sitting in groups of four. Originally, the Better Education Inc. Classtalk wired system was used (Abrahamson, 1998) as the CCS, but this was replaced by Varitronics' Personal Response System (PRS) (now distributed by Avantec), a fairly simple but cheap and effective system based on infrared transmitters and receivers. Typically PRS is used to poll the class using multiple-choice questions. It also allows students to indicate their level of confidence although this feature is not examined in this evaluation. The results of the poll are collated in the lecturer's computer and displayed as a histogram using a data projector. The lecture theatre, called the InterActive ClassRoom, also has advanced multimedia facilities. A more detailed technical description is available in Comlekci et al. (1999).

\section{Student Intake and First Year Curriculum}

The intake to first year Mechanical Engineering at the University of Strathclyde is typically between 110 and 120 students with around $10-15 \%$ female. The first-year curriculum consists of 12 credits. Two of these credits are electives that allow the students to take any class they are interested in. Of the remaining 10 credits, there are three core credits (engineering mechanics and thermo-fluids), three credits for design, two credits for mathematics, one for computing and engineering analysis and one for electronics.

\section{Description of the Engineering Mechanics Class}

The engineering mechanics class is a two-credit first-year class run over two 12-week semesters, consisting of two two-hour sessions per week. The study took place during the first semester. The first three weeks of the class comprise a review of the teaching and learning methodologies to be used, and of (high) school material. This review allows the CCS to be 
introduced using school-based subject material with which students feel fairly comfortable. As part of this review students are encouraged to reflect on their own learning, and this emphasis continues throughout the semester. The intention is that students quickly realise that their previous understanding of basic concepts is deficient; it is hoped that this will motivate them to actively participate in the classes. During the semester new topics are introduced in two-week sequences (Weeks $4 \& 5,6 \& 7$ and $9 \& 10$ ) separated by tutorials for problem-solving. The problem-solving is highly structured using a multiple-representation heuristic (problems are solved using a detailed procedure which requires the students to think in different ways-pictorially, conceptually and mathematically). The class is based on an established, introductory mechanics textbook supplemented by overheads that are made available on the Web.

Figure 1 gives examples of the concept tests that are used to introduce the notion of 'tension' in a rope in the first few weeks. Although most students have a common-sense

\section{What is approximately the tension in the rope?}

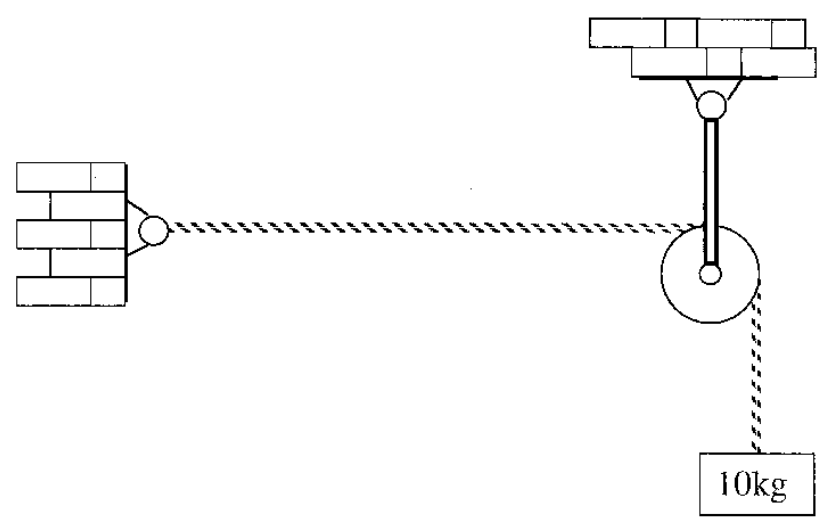

1. $0 \mathrm{~N}$

2. $100 \mathrm{~N}$

3. Depends how flexible the rope is

FIG. 1a. 


\section{What is approximately the tension in the rope?}

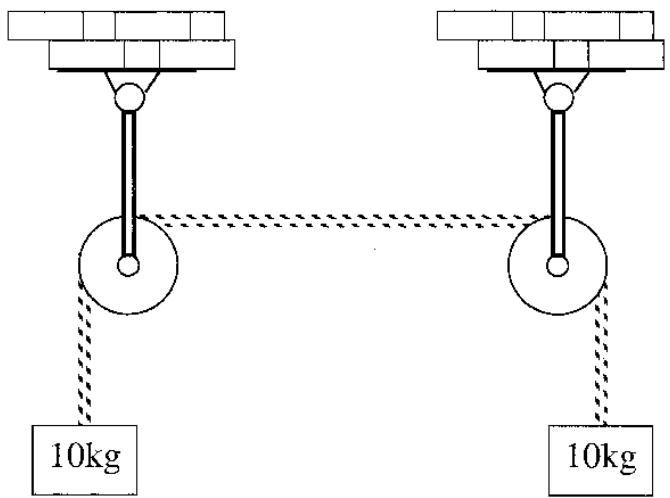

1. $0 \mathrm{~N}$

2. $50 \mathrm{~N}$

3. $100 \mathrm{~N}$

4. $200 \mathrm{~N}$

FIG. 1b. Typical concept question.

understanding of tension from everyday experience, using the concept in applications where values have to be deduced often causes major difficulty. The first question (Fig. 1a) sets the scene. The mass is $10 \mathrm{~kg}$, so the weight of the mass is approximately $10 \mathrm{~kg} \times 10 \mathrm{~m} / \mathrm{s}^{2}=100$ Newtons (N). Since the mass is stationary the tension in the rope must balance the weight of the mass, so the correct answer is 2 in this question. Typically, over $95 \%$ of the students will correctly answer. This concept test is then followed by that shown in Fig. 1b with two $100 \mathrm{~kg}$ masses. The majority of students will choose answer 4 , that is, the tension is now doubled, and will be astonished to find that the tension is still $100 \mathrm{~N}$. The discussion that follows is aimed at getting the students to understand the use of a simple 'force diagram', rather than 'common sense', to argue through this situation. Most will understand the force diagram argument and begin to start questioning common sense in the use of Newton's Laws of Motion. 
The engineering mechanics class sessions are all taught in the InterActive ClassRoom. Each session comprises a mixture of mini-lectures, question and answer sessions using PRS, demonstrations, technical videos, computer simulations and problem-solving. Active and collaborative learning are actively encouraged both in and out of class. In the InterActive ClassRoom students are organised into peer groups of four and they sit in these groups throughout the year. Class differences in responses to concept questions (displayed by histogram) are used as the trigger for discussion amongst students in their peer groups (peer instruction) and to initiate teacher-facilitated discussions across groups (class-wide discussion). A relaxed atmosphere is encouraged in class and music is sometimes played.

Students are also expected to work in their group outside class, and to encourage this group homework exercises and simple design studies are used. The peer groupings are decided at the start of the academic year from a simple questionnaire: this attempts to match students who are in the same halls of residence, to mix students who have different computing skills, and to mix students who have entered from fifth or sixth year of school, or from further education. In terms of gender, the resulting groups are normally 'all male', 'all female' or 'mixed' (but always with two male and two female members). On the first day of the semester students are introduced to their groups and together take part in a full day of ice-breakers and team-building exercises around the campus.

The interactive sessions are normally facilitated by two lecturers who each take a topic in turn. Both lecturers are present at all times-this has been found to be very helpful. The intake in 2000-2001 consisted of 117 students initially, with three dropping out during the first semester.

\section{Study Design and Methodology}

\section{Design}

The main aim of this study was to explore students' perceptions of the effects of two different classroom discussion sequences on their understanding and motivation. Table I clarifies the learning and discussion sequences as used by Mazur and the PERG respectively.

TABLE I. The sequence of activities for peer instruction and class-wide discussion

Peer instruction: Mazur sequence

1. Concept question posed

2. Individual Thinking: students given time to think individually (1-2 minutes)

3. Students provide individual responses

4. Students receive feedback-poll of responses presented as histogram display

5. Peer Discussion: students instructed to convince their neighbours that they have the right answer

6. Retesting of same concept

7. Students provide individual responses (revised answer)

8. Students receive feedback - poll of responses presented as histogram display

9. Lecturer summarises and explains 'correct' response
Class-wide discussion: PERG sequence

1. Concept question posed

2. Peer Discussion: small groups discuss the concept question (3-5 mins)

3. Students provide individual or group responses

4. Students receive feedback-poll of responses presented as histogram display

5. Class-wide Discussion: students explain their answers and listen to the explanations of others (facilitated by tutor)

6. Lecturer summarises and explains 'correct' response 
The main differences in the question/discussion methods are that Mazur starts with individual thinking and responses to concept tests, followed by peer discussion. He does not usually utilise class-wide discussion. In contrast, the PERG usually starts with peer discussion and ends with class-wide discussion. Although we have taken these discussion sequences from the writings of these researchers, it should be noted that these are 'ideal types', and that Mazur, and certainly the PERG, do not stick rigidly to a specific sequence.

In order to evaluate the effects of these differences, the first semester engineering mechanics class was divided up so that in certain two-week blocks only the PERG sequence was used and in other two-week blocks only peer instruction was used.

$\begin{array}{ll}\text { Weeks 1-3: } & \text { Overview and Revision: both discussion sequences } \\ \text { Weeks } 4 \& 5: & \text { New material: both discussion sequences } \\ \text { Weeks } 6 \& 7: & \text { Class-wide Discussion (the PERG sequence) } \\ \text { Week 8: } & \text { Extra tutorials for problem-solving } \\ \text { Weeks } 9 \& 10: & \text { Peer Instruction (the Mazur sequence) } \\ \text { Weeks } 11 \& 12: & \text { Extra tutorials for problem-solving }\end{array}$

\section{Investigative Methods}

Three methods were used to explore students' perceptions and motivations. Firstly, semistructured interviews were held with five focus groups of six students (30 students). This gave a sample size of $25 \%$ of the class enrolment. Two groups (male) were interviewed immediately after an interactive classroom session and two groups (female) were interviewed later in the same week that the interactive session occurred. These groups were all UK students, and the 'all male' and 'all female' selection was intended to reveal any gender differences in students' perceptions. The fifth group comprised both foreign and UK students and it was of mixed gender. Each group was interviewed twice-once while class-wide discussion was being used (week 7) and once during the peer instruction (week 10). Three interviewers conducted the interviews. One of the authors (DJN) carried out interviews and coordinated the interviews conducted by the other two interviewers. The other author (JTB), who lectured on the class, did not take part in the interviews or in the evaluation.

The second evaluation method was a survey that comprised 36 statements. The statements were derived from an analysis of the semi-structured interview data. Important issues raised by students in the interviews were identified and formulated into single sentence statements, and a five-point Likert scale was linked to each statement. The range descriptors of the scale were: strongly agree, agree, neither agree nor disagree, disagree, strongly disagree. While most of the statements were phrased in the positive sense, some were also phrased in the negative to discourage rote responses. At the end of the semester, while in class, students were given a (two-page) form with the statements and the rating scale. They were asked to fill in the form individually, indicating agreement or disagreement with the each of the statements. They did not put their names on the form although they did give some biographical data-prior educational experience and gender. Five of the most important statements asked students to provide, in addition to a rating, a short reason for the answer they gave. The aim of the survey was to be able to quantify the views expressed in the interviews and to ascertain what was a minority opinion or indicative of general class agreement. Only the data from 15 of the survey statements are reported in this study (see Table II).

The third evaluation method involved the use of a critical incident questionnaire. This was adapted from Brookfield (1995) and comprised a single sheet of A4 with five questions and space for comments. This was distributed to students in week 5 . In that week both 
discussion sequences were in use in class. An interactive session in that week was stopped 10 minutes early and students were asked to fill in the questionnaire without writing their name. A typical question was: At what moment in the class did you feel most engaged with what was happening? Why? The intention of this evaluation was to find out about students' immediate experiences in a typical class.

\section{Results}

In the interviews and survey, all students reported that the teaching methods used in the wired classroom helped them improve their understanding of difficult concepts when compared with conventional lecture classes. The reasons they gave included more active involvement in learning, more time to think and reflect in class (i.e. when given a concept test), the motivational effects of receiving immediate feedback (the histogram display) and the feeling that the teacher was adapting instruction in response to their learning needs. These findings are reported in detail elsewhere (Boyle \& Nicol, 2003). The main focus of this article is with how students perceived the effects of the different discussion sequences-peer instruction and class-wide discussion-on their conceptual learning and motivation. Hence, we begin with an examination of the influence of peer discussion on learning.

\section{Peer Discussion}

Peer discussion was common to both peer instruction and class-wide discussion. In the interviews all students reported that dialogue with other students in peer groups was central to the development of their understanding of concepts and ideas. Peer discussion provided opportunities to think about the problem in more detail, to explore alternative viewpoints and problem-solving approaches, and to ask for and hear different explanations. When students were asked 'how peer discussion actually leads to a choice of answer', most students talked about the choice being based on the best argument.

Different people put forward different ideas and then maybe one of them will say-'well that can't work because of this ...'-it's exchanging ideas, we usually get an answer and discuss it ... you've got to be able to put forward a good argument for why your answer is better than his ... you can't just guess because you'll get picked on to explain it ... you've got to think about it ... the one that's most convincing is usually selected ... the argument has to be strong and logical.

In general, the students reported that peer discussion resulted in their reconceptualising important principles as well as learning about new methods and approaches to problem-solving. Some students also noted that it was easier to admit lack of understanding of a concept to peers rather than to the teacher and this opened up the opportunity for discussion.

If a peer understands it and you don't, you can discuss it and come to a solution ... it saves you having to stick your hand up and say to the lecturer ... I have no idea what you are talking about.

A significant number of students in the focus groups made classic psychology textbook responses when talking about the value of peer discussion by referring to a form of 'scaffolding' by fellow learners (e.g. as described by Vygotsky, 1978). They talked about how it was easier to understand a concept explained by a fellow student who had just grasped it, than the same concept explained by the lecturer who was on a 'much higher plane.' 
I think you can learn a lot easier from the people that are the same age as you ... if they've just grasped it then they can explain it in sort of easier terms than the lecturer ... you suddenly understand it when a minute before it was difficult.

The language used by other students was often cited as the critical component in fostering new insight and understanding. Students maintained that peer explanations were often more accessible than teacher explanations.

It's a language that you can understand between two students ... whereas if it's put forward by the professor he knows the deep meaning behind everything-he might make it more complicated than it needs to be.

The survey data confirmed that the effects of peer discussion on learning were not just experienced by the students in the focus groups. Nearly all the students agreed with the statement that 'discussing PRS [personal response system] questions with other students in class helps me to understand better the subject matter' ( $92 \%$ agree, $0 \%$ disagree) and that 'that hearing other students explain problems in their own words when working in small groups helps me to learn' ( $82 \%$ agree, $4 \%$ disagree). Table II presents data for all the survey statements (note: there were no significant male-female differences across the survey data).

TABLE II. Student responses to the end of semester survey

\begin{tabular}{lccc}
\hline & & Students & Students \\
No. & Survey statement & agree (\%) & disagree $(\%)$ \\
\hline
\end{tabular}

1. Discussing PRS questions with other students in the class helps me to understand better the subject matter

2. Hearing the students explain problems in their own words when working in our small groups helps me to learn

3. Everyone in our group usually has an opportunity to express their opinion on the question being discussed

4. Some students always dominate the discussion in small groups

5. Having a number of different viewpoints in the small groups often leads to confusion

6. Using PRS, it is better to answer the concept question individually before discussing the question in small groups

7. Group discussion after making an individual response leads to deeper thinking about the topic

8. Using PRS, it is better to start with a small group discussion before making an individual response

9. The best interaction method depends on the difficulty of the question

10. A class discussion using a microphone is an important aspect of the PRS class

11. I pay more attention in class when I know I might have to answer questions with the microphone

12. Hearing other students' explanations by microphone often confuses me

13. I like having to explain the answers to the PRS questions using the microphone

14. It is important that the teacher clearly explains which is the right answer and why after a class discussion using the microphone

15. Using PRS helps the teacher become more aware of student difficulties with the subject matter

$\begin{array}{lc}92 & 0 \\ 82 & 4 \\ 83 & 2 \\ 27 & 44 \\ 31 & 37 \\ 82 & 5 \\ 90 & 2 \\ 13 & 60 \\ 43 & 17 \\ 40 & 26 \\ 52 & 15 \\ 37 & 31 \\ 10 & 61 \\ 100 & 0 \\ 80 & 4\end{array}$

Note: Figures are derived from responses to a 5-point Likert scale $(1-5$ with $1=$ strongly agree and $5=$ strongly disagree). Responses 1 and 2 have been combined to represent the percentage of students 'agreeing' with each statement and, similarly, responses 4 and 5 represent the percentage 'disagreeing'. The ordering of statements in the table follows the text and was not the order of presentation to students. 
Discussing concept questions in small groups not only enhanced students' conceptual understanding but it also proved to be a powerful motivating force. In week 5 students were asked the question (Critical Incident questionnaire), 'At what moment in the class did you feel most engaged with what was happening? Why?' Over 100 students were in the class that day, and over $90 \%$ wrote that they felt most engaged when they were interacting and discussing problems with other students. Where students provided a reason for their answers, they invariably mentioned that through discussion they became more involved, or learned from others, or that discussion helped them to think through a problem or discover alternative approaches to solving a problem. The following are some typical responses to this question:

Using PRS to talk ... it is interactive ... we put forward our own thoughts but if we are wrong we can learn from other students.

I felt most engaged when answering the PRS questions. This is because I didn't fully understand what was going on and this gave me a chance to talk and think about the problem with those in my group.

When people in the group have strong opinions on a PRS answer but answers are different and you have to explain your thought processes to the others.

The data reported above support the argument that, at least from the student perspective, peer discussion helps them develop their understanding of concepts and ideas. Nonetheless, despite the general enthusiasm, a number of the students identified difficulties with peer discussion. In the survey a number of the statements were constructed to throw light on how students perceived the workings of their small group. The data from these statements is quite revealing. Whereas the majority of students agreed with the statement that 'everyone in our group usually has an opportunity to express their opinion on the question being discussed' ( $83 \%$ agree; $2 \%$ disagree), around one-quarter of the students also agreed with the statement that 'some students always dominate the discussion in small groups' (27\% agree; $44 \%$ disagree). Moreover, a similar number agreed that 'having a number of different viewpoints in the small group often leads to confusion' (31\% agree; $37 \%$ disagree).

The next section tries to throw some light on these points by teasing apart the effects of peer discussion as it occurred within the different discussion sequences. This is followed by an examination of the effects on learning of class-wide discussion.

\section{The Initial Discussion Sequence}

Almost all the students interviewed expressed a preference for starting the concept test with individual thinking and an individual response, rather than with peer discussion. Students cited two reasons for this. First, the requirement to make an individual response meant that they were forced to think about the problem, and to formulate their own reason for their selected answer, prior to the group discussion. In contrast, with an initial peer discussion the students felt that they might be more likely to be passive, and be influenced by the more confident students, and to unthinkingly accept the answer that these students suggested. Second, having constructed their own answer, students felt they benefited more from the subsequent peer discussion. They would be more likely to engage in dialogue and to provide reasons for, and defend, their ideas and they would be more likely to be able to identify gaps in their thinking.

The survey at the end of the semester substantiated, and elaborated upon, the general findings of the interview data. The majority of students agreed that it 'is better to answer the (concept) question individually before discussing the question in small groups' ( $82 \%$ agree, 
$5 \%$ disagree). Students were asked to write a reason for their response to this survey statement. From the $90 \%$ who responded, $80 \%$ made comments that were consistent with those expressed by the students interviewed in the focus groups. The following is a representative sample of the written responses:

By the time you discuss it you all have your own opinions so you are less likely to just agree with other people.

You can see where you have gone wrong in your original answer and learn from it.

It can help you identify misconceptions if you think individually first.

It gives you different opinions rather than one group member knowing the answer and telling you.

It makes you reason your point of view before explaining it to others.

In the survey most students also agreed that 'a group discussion after an individual response leads to deeper thinking about the topic' (90\% agreed, $2 \%$ disagreed).

As a cross-check on which interaction method was preferred, students were also asked in the survey to respond to the statement, 'using PRS it is better to start with a small group discussion before making an individual response'. As one would expect, the majority disagreed with this statement (13\% agreed; $60 \%$ disagreed); and when students were asked to provide a written reason for their response the reasons adduced were very consistent with the comments made above. A typical comment was:

I don't think that everyone would think about the question properly ... some people would go with other people's answers.

Despite the general agreement that it is better to start the concept test with an individual response, a small number of students in the interviews argued that for very difficult concept questions it might be better to start with group discussion. The rationale was that if you couldn't make much, or any, progress on your own then discussion with peers might allow a pooling of intellectual resources which might help students get started on the problem. As a check on the generality of this view the end of semester survey included the following statement: 'the best interaction method depends on the difficulty of the question'. There was a mixed response to this statement, with more agreeing than disagreeing (43\% agreed; $17 \%$ disagreed). Students were also asked to give a reason for their response to this statement. From those who commented, the majority maintained that it was always better to start with an individual response, but again a small minority argued that if the question was really difficult then an individual response may not be possible and a group discussion might help to unpack the question.

Sometimes you don't know where to start with a question on your own and you just guess.

Some questions are too difficult to be handled alone on the first attempt.

\section{Class-wide Discussion}

In class-wide discussion, the normal procedure is for the tutor to use the computer to identify an individual or a group and then to ask that individual or group member to explain the reasoning behind their answer to a concept question using a microphone. The tutor then tries to facilitate dialogue across the peer groups. Students are encouraged to ask questions of 
other students or the tutor during this time, and both correct and incorrect answers might be discussed.

In the focus group interviews students expressed mixed views regarding class-wide discussion, and this was reflected in the survey data where there was a mixed reaction to the statement, 'a class discussion using the microphone is an important aspect of the PRS class' ( $40 \%$ agree, $26 \%$ disagree). On the positive side, many students said that they liked hearing explanations-for correct and incorrect answers-from those outside their own group.

You are learning from people round you ... maybe someone at the other side of the room that understands a lot better than you, or the members of your group, and that [person] starts explaining it.

As with the peer group discussions these students felt that other students' explanations helped them grasp difficult concepts, and that this was especially helpful when the students that were presenting used language that was more accessible (than that used by the teacher).

The class discussions are generally good and it is very useful to hear other students describing and justifying the reasons for their answer. It is useful to hear others at our own level rather than just the lecturer all of the time.

Also, some students maintained that knowing that one might be called upon to explain the thinking behind a response encouraged them to formulate explanations in advance and that this increased attention levels during the class. Over half of the students agreed with this point in the survey: 'I pay more attention in class when I know I might have to answer questions with the microphone' (52\% agree, $15 \%$ disagree).

Despite identifying the benefits, the students interviewed were quick to point out the drawbacks to class-wide discussion. Some students felt it took too much time and that it was easy to drift away from the question or get confused about the answers under discussion.

The answers to the problems can sometimes get lost during class discussion particularly when there are a number of potential answers being discussed. If the discussion goes on for too long then interest can diminish, it can also lead to confusion ... it is easy to lose track of the main arguments.

Others felt that the students presenting an explanation often did 'not know what they were talking about', and that this led to confusion: 'we get confused and lost in the arguments'. The effectiveness of class-wide discussion, according to these students, depended on which students were selected by the teacher.

It relies on the individual being able to explain their ideas clearly. A student with a correct answer but a poor explanation, or a student with the incorrect answer but with a convincing explanation, could cause confusion or lead others to disagree with the correct answer.

The survey data confirmed that confusion was a problem in class-wide discussion, with a significant proportion of students agreeing with the statement, 'hearing other students' explanations by microphone often confuses me' (37\% agree, $31 \%$ disagree).

In the interviews, many students reported that class-wide discussion was in some way threatening, and some felt that it significantly increased their anxiety levels. The requirement to explain your answer to the class using a microphone was not liked by some students, and especially if you had not volunteered. This was reinforced by the survey, where most students disagreed with the statement, 'I like having to explain the answers to PRS questions using the microphone' (10\% agree, $61 \%$ disagree). 
When, in the focus groups, the students themselves were asked to compare the peer group discussion with the class discussion, the majority indicated a preference for the former. The reasons for this were generally related to the better opportunity for dialogue afforded by the small group situation.

It [small group discussion] is more of a discussion rather than just hearing various people airing a number of possibly correct or incorrect opinions. If someone does make an incorrect statement using the microphone it is not as easy to discuss, correct or understand the statement as it would be in a smaller group discussion.

It is better without whole class discussion ... it is not really a discussion but an (interesting) opportunity to hear other people's points of view.

When students were asked, 'when is the best time to use class-wide discussion', many maintained that it was most useful when the histogram feedback showed that the class was clearly divided between two competing answers. This was contrasted with the situation where class responses were distributed across a number of the multiple-choice alternatives. The latter situation was considered more likely to lead to confusion, especially if each alternative was subsequently explored in the class discussion. Other students argued that it was better used with very difficult concepts. In both cases-where there was a clear division of opinion and in cases of difficult problems-class-wide discussion extended the time available to explore and elaborate the topic through hearing different viewpoints.

The main recommendation made by students with regard to class-wide discussion in the interviews, and unanimously confirmed by the survey, is that 'the teacher clearly explains which is the right answer and why after a class discussion using the microphone' $(100 \%$ agree):

It is important to get the final answer after having your own understanding and given your own answer and had the class discussion ... you've thought about it in so many different ways and you've heard the logic of different answers ... but which one is right?

Class-wide discussion is helpful but as long as they [the lecturers] ... give the right answer at the end and explain how it works and what the thinking behind it is, what the logic is.

It is very important that the lecturer gives a clear summing up to the problem, stating clearly the correct answer along with the reasons why. For example, confusion may arise if a student in the class discussion has the correct answer but can only offer a very poor explanation as to why that is the correct answer.

Finally, a more general finding from the survey data was the students' belief that 'using PRS helps the teacher become more aware of students' difficulties with the subject matter' $(80 \%$ agree; $4 \%$ disagree).

\section{Discussion}

The main goal of this article was to report on the comparison of the discussion sequences used at Harvard and Massachusetts. This comparison indicated that peer instruction was perceived by students to be more beneficial to learning than class-wide discussion. In addition, peer instruction proved less prone to some of the difficulties associated with class-wide discussion. With class-wide discussion, students could easily become confused if the class responses were distributed across a number of multiple-choice alternatives, and each 
of these alternatives became the subject of class discussion; and if the class discussion was prolonged for too long students were more likely to lose interest and motivation. Peer instruction is also less demanding on the teacher than class-wide discussion. With class-wide discussion the teacher must facilitate interaction across numerous small groups, and this requires considerable skills in classroom management.

Despite the overall preference for peer instruction, some students still valued hearing different peer groups publicly discuss their conceptual reasoning; and there were situations where students felt that class-wide discussion might have advantages over peer instruction. For example, an early peer discussion was seen as valuable when the concept question was very complex and students had difficulty in selecting from the multiple-choice alternatives. In this situation, hearing, discussing and reacting to other viewpoints helped students to formulate an initial interpretation of the concept question. However, identifying in advance which concept questions will pose sufficient difficulty to warrant starting the sequence with a peer discussion (rather than individual reflection) will prove challenging to teachers. Students also recommended strategies to guard against some of the difficulties associated with class-wide discussion: for example, making sure that the correct solution is clarified at the end of the class-discussion, and only using this method when the class is divided across a few response alternatives.

The students' own analyses of their experiences of learning through peer instruction are remarkably consistent with (and, at times, even descriptive of) the research literature on social constructivism (e.g. Doise \& Mugny, 1984; Anderson et al., 1996). Most students maintain that the initial step in peer instruction provides an opportunity to formulate an individual interpretation of the concept in relation to the test question. In this first step, students begin to 'construct' their own mental model, or interpretation, of the concept. According to the students, the next step, peer discussion, enhances this constructive process. The students are told: 'convince your neighbours that you have the correct answer'. The students bring differing interpretations, and ways of approaching the concept question, to the peer discussions. They report trying to reach a position about the correct answer through a critical analysis of the thinking behind these different interpretations.

Many of the published articles that take a social constructivist perspective in relation to peer interaction invoke 'socio-cognitive conflict' as the mechanism to explain how superior conceptual understanding is brought about (see Anderson et al., 1996; 2001; Palinscar, 1998). In peer discussion, points of disagreement and agreement emerge as students assert, challenge and justify different points of view. This results in students jointly negotiating or constructing an improved conceptualisation based on a reconciliation of their different interpretations (conceptualisations) (Doise \& Mugny, 1984; Anderson et al., 1996). These improved conceptualisations are internalised and then tested out again in subsequent tasks.

This model might explain why class-wide discussion is less effective than peer instruction. In class-wide discussion students are not given an opportunity to generate their own conceptualisation (or mental model) in relation to the concept test. Hence, there is less conceptual conflict when peer discussion begins. As students report, they are more likely to acquiesce and accept the dominant interpretation. Further research is required, however, to confirm this hypothesis. This research might entail examining samples of actual dialogue generated within peer groups as they discuss a concept test (e.g. under conditions where they either have or do not have an opportunity to formulate an initial position).

As well as the joint negotiation of improved conceptualisations, there is also evidence from the student interviews of 'scaffolding', where the more advanced, or more knowledgeable, students help those less advanced to achieve higher levels of conceptual acquisition (see, Bruner, 1985). The language used by students in discussion appears to play a crucial role 
here. In the research literature, socio-cognitive conflict and scaffolding are often proposed as alternative explanations for peer learning (Doise \& Mugny, 1984; Anderson et al., 1996; Palinscar, 1998). The fact that these processes appear to co-exist in this study is promising, although it requires further investigation. What is also interesting is that both these processes are triggered using simple multiple-choice tests that are normally associated with surface rather than deep learning.

In this study, class-wide discussion (weeks $6 \& 7$ ) preceded peer instruction (weeks $9 \&$ 10) in the teaching programme. This might lead one to suspect that this ordering influenced the results. While this is possible, it should be remembered that students had experience of both discussion methods over the first five weeks of teaching, so they were quite familiar with both methods. Also, an order effect could hardly account for the range of differences across discussion methods discovered here. A more interesting issue is how an increase in class size might influence the results. In this study there were around 100 students per class. The above findings suggest that, if numbers increased, students would be more likely to disengage and it would become progressively more difficult for the teacher to manage class-wide discussion. Therefore, it is arguable that the advantages of using peer instruction would be even greater with larger classes.

A key question remains: what role does the CCS technology play in these processes? There are obvious practical benefits associated with CCS technology when student numbers are large. Firstly, students can make an independent response to a concept test, using the handsets, without knowing the nature of other students' responses. A show of hands (or flash cards to signal responses) would normally be less effective in concealing others' responses; and this study has shown that when students know the responses of others (before they have settled on their own answer) peer discussion is less effective. Secondly, the feedback that is displayed after a concept test is immediate and public and involves a poll of all students. Without CCS these conditions would be difficult to achieve; collating responses would certainly be more time-consuming, and in large classes some students might remain hidden and passive. Thirdly, CCS produces a permanent record of student responses to concept tests. These logs, if analysed, could be used to help teachers to map out recurrent concept difficulties in the discipline together with appropriate teaching strategies. Fourthly, CCS is believed to make it easier to manage cycles of input and discussion in a time-efficient way (Dufresne et al., 1996).

Despite the practical benefits of CCS technology, it is clear that the learning gains reported in this study were not the result of the technology alone. Rather, these gains were the result of the application in class of teaching and learning principles centred on active engagement and dialogue which were supported by CCS technology. Many of the advantages of this style of learning could therefore be retained (but perhaps less easily) even without a CCS. Indeed, this study might be seen to provide further evidence for, and to reinforce, much of what Bligh (1972) advocated with regard to effective lecturing using interactive methods over 30 years ago.

Correspondence: Dr D. J. Nicol, Centre for Academic Practice, Graham Hills Bldg, 50 George St, Glasgow, G1 1QE, UK; e-mail: d.j.nicol@strath.ac.uk

\section{REFERENCES}

Abrahamson, A.L. (1998) An overview of teaching and learning research with classroom communication systems, paper presented at the International Conference of the Teaching of Mathematics, Samos, Greece.

Anderson, T., Howe, C. \& Tolmie, A. (1996) Interaction and mental models of physics phenomena: evidence from dialogue between learners, in: I. OAKHILl \& A. GaRnham Mental Models in Cognitive Science (London, Taylor \& Francis). 
Anderson, T., Howe, C., Soden, R., Halliday, J. \& Low, J. (2001) Peer interaction and the learning of critical thinking skills in further education students, Instructional Science, 29, pp. 1-32.

BLIGH, D. (1972) What's the Use of Lectures? (Harmondsworth, Penguin).

Bligh, D. (2000) What's the Use of Lectures? (San Francisco, CA Jossey-Bass).

Boyle, J. \& Nicol, D.J. (2003) Using classroom communication systems to support interaction and discussion in large class settings, Submitted for publication.

Brookfield, S.D. (1995) Becoming a Critically Reflective Teacher (San Francisco, CA, Jossey-Bass).

Brown, J.S., Collins, A. \& Duguid, P. (1989) Situated cognition and the culture of learning, Educational Researcher, 18, pp. 32-42.

BRumby, M.N. (1984) Misconceptions about the concept of natural selection by medical biology students, Science Education, 68, pp. 493-503.

BRUNER, J. (1985) Vygotsky: a historical and conceptual perspective, in: J.V. WeRTSCH (Ed.), Culture, Communication and Cognition (Cambridge, Cambridge University Press).

Comlekci, T., Boyle, J.T., King, W., Dempster, W., Lee, C.K., Hamilton, R. \& Wheel, M.A. (1999) New approaches in mechanical engineering education at the University of Strathclyde in Scotland: I-Use of technology for interactive teaching, in: G. SAGLAMER et al. (Eds) Engineering Education in the Third Millennium, pp. 540-545 (Istanbul, Leuchtturm-Verlag).

Crouch, C.H. \& Mazur, E. (2001) Peer instruction: ten years of experience and results, American fournal of Physics, 69, pp. 970-977.

DeCorte, E. (1996) New perspectives on learning and teaching in higher education, in: A. BURGEN (Ed.) Goals and Purposes of Higher Education (London, Jessica Kingsley).

Doise, W. \& Mugny, G. (1984) The Social Development of the Intellect (Oxford, Pergamon).

Dufresne, R.J., Gerace, W.J., Leonard, W.J., Mestre, J.P. \& Wenk, L. (1996) Classtalk: a classroom communication system for active learning, fournal of Computing in Higher Education, 7, pp. 3-47.

Edwards, H., Smith, B.A. \& WebB, G. (2001) Lecturing: case studies, experience and practice (London, Kogan Page).

Glaser, R. (1990) The re-emergence of learning theory within instructional research, American Psychologist, 45, pp. 29-39.

HAKE, R.R. (1998) Interactive engagement versus traditional methods: a six thousand student survey of mechanics test data for introductory physics courses, American fournal of Physics, 66, pp. 64-74.

Halloun, I.-A. \& Hestenes, D. (1985) The initial knowledge state of college physics students, American Fournal of Physics, 53, pp. 1043-1055.

LAve, J. \& Wenger, E. (1991) Situated Learning: legitimate peripheral participation (Cambridge, Cambridge University Press).

Macgregor, J., Cooper, J.L., SMith, K.A. \& Robinson, P. (2000) Strategies for Energizing Large Classes: from small groups to learning communities (San Franscisco, CA, Jossey-Bass).

Matthews, R.S. (1996) Collaborative learning: creating knowledge with students, in: R.J. MENGES, M. Weimer \& Associates (Eds.) Teaching on Solid Ground (San Fransisco, CA, Jossey-Bass).

MAZur, E. (1997) Peer Instruction: a user's manual (Englewood Cliffs, NJ, Prentice Hall).

McDermott, L.C. (1984) Research on conceptual understanding in mechanics, Physics Today, 37(7), pp. 24-32.

Palinscar, A.S. (1998) Social constructivist perspectives on teaching and learning, Annual Review of Psychology, 49, pp. 345-375.

ReITER, S.N. (1994). Teaching dialogically: its relationship to critical thinking in college students, in: P.R. Pintrich, D.R. Brown \& C.E. WeInstein (Eds) Student Motivation, Cognition and Learning (Hillsdale, NJ, Lawrence Erlbaum).

RESNICK, L.B. (1989) Knowing, Learning and Instruction: essays in honour of Robert Glaser (Hillsdale, NJ, Lawrence Erlbaum).

Vygotsky, L.S. (1978) Mind in Society (Cambridge, MA, Harvard University Press).

West, L.H.T. \& Pines, A. L. (Eds) (1985) Cognitive Structure and Conceptual Change (New York, Academic Press). 
